\title{
Measuring abortion-related mortality: challenges and opportunities
}

\author{
Caitlin Gerdts ${ }^{*}$, Ozge Tunçalp², Heidi Johnston² and Bela Ganatra ${ }^{2}$
}

\begin{abstract}
Two recent efforts to quantify the causes of maternal deaths on a global scale generated divergent estimates of abortion-related mortality. Such discrepancies in estimates of abortion-related mortality present an important opportunity to explore unique challenges and opportunities associated with the generation and interpretation of abortion-related mortality estimates. While innovations in primary data collection and estimation methodologies are much needed, at the very least, studies that seek to measure maternal deaths due to abortion should endeavor to improve transparency, acknowledge limitations of data, and contextualize results. As we move towards sustainable development goals beyond 2015, the need for valid and reliable estimates of abortion-related mortality has never been more pressing. The post-MDG development agenda that aims to improve global health, reduce health inequities, and increase accountability, requires new and novel approaches be tested to improve measurement and estimation of abortion-related mortality, as well as incidence, safety and morbidity.
\end{abstract}

Over the last decade, global levels of maternal mortality have decreased [1]. Improved levels of overall health, increased availability of medical abortion, and efforts to improve access to safe abortion and post-abortion-care in some countries may have contributed to reductions in abortion-related mortality. Evaluating the extent of progress however, remains problematic due to challenges in obtaining valid and reliable data and difficulties interpreting existing data.

Two recent efforts to quantify the causes of maternal deaths on a global scale generated divergent estimates of abortion-related mortality. Despite overlapping confidence intervals, the point estimate for the proportion of maternal mortality attributable to abortion from the 2013 IHME estimate (14.9 \%, 95 \% Uncertainty Interval (UI): $13.5,17.6)$ is nearly twice that estimated for the 2003-2012 period by the WHO (7.9\%, $95 \%$ UI: 4 . $7,13 \cdot 2)[2,3]$. Indeed, the two papers examined different time periods, employed distinct statistical techniques, and analyzed discrete data sources. Nevertheless, such discrepancies in estimates of abortion-related mortality present an important opportunity to explore unique challenges

\footnotetext{
* Correspondence: cgerdts@ibisreproductivehealth.org

'Ibis Reproductive Health, Oakland, California, USA

Full list of author information is available at the end of the article
}

and opportunities associated with the generation and interpretation of abortion-related mortality estimates.

Estimates of abortion-related mortality are primarily developed from four types of data sources: confidential enquiries, vital registration data, verbal autopsy- a systematic tool used to collect health information from lay-person informants and assess causes of death [4] and facility-based data sources. National-level confidential enquiries into causes of maternal mortality only occur in a handful of countries. While vital registration systems are considered the gold-standard for mortality measurement, they have been shown to miss up to 30$50 \%$ of all maternal deaths. In addition, $75 \%$ of global births take place in countries without existing vital registration systems [5-7]. For both facility-surveys and verbal autopsies, willingness to participate in studies, misclassification, and underreporting present obstacles to the collection of robust data. In countries where unsafe abortion is common, it is often also legally restricted, and/or highly stigmatized. In these settings, fear of legal or social repercussions, lead women who experience abortion-related complications to be less likely than women experiencing other kinds of pregnancy-related complications to seek care in medical facilities [8-11]. This type of bias-selection biasresults in an absolute undercount of abortion-related deaths (and a relative undercount of abortion-related 
deaths compared with other causes of maternal deaths) from facility-based data [12].

While verbal autopsy studies may provide some advantages over facility-based data in the estimation of community-level distribution of abortion-related mortality, concerns over selection bias persist: fear of social and legal ramifications may lead family members of women who suffered an abortion-related death to be less likely to participate in studies as compared to family members of women who died from other maternal causes $[13,14]$. Additionally, for both data sources, because complications from induced abortion often manifest similarly to other obstetric complications (spontaneous abortion, hemorrhage, sepsis) abortion-related deaths are prone to being misclassified as non-abortion-related maternal deaths, or even as non-maternal deaths-again resulting in absolute and relative underestimates of abortion-related deaths [11]. Finally, in both facility-based and verbal autopsy studies, abortion-related deaths are more likely than the other maternal causes to be classified as "unknown" [15]. By virtue of being classified as "unknown", abortionrelated deaths are misclassified as non-abortion-related deaths, leading to an underestimate of abortion-related deaths as a proportion of all maternal deaths.

In addition to the above-mentioned concerns, there are limitations to what can be interpreted from estimates of abortion-related deaths. First, global estimates of cause-specific maternal death present abortionrelated mortality as a proportion of total mortality. Any increase or decrease in abortion-related mortality is relative to other causes and does not necessarily imply that abortions have become safer or less safe with respect to mortality. Second, drawing inference about the safety of abortion from estimates of abortion-related mortality requires a more comprehensive understanding of the circumstances within which abortions take place. Lower or higher levels of abortion-related mortality could be driven by multiple, non-mutuallyexclusive factors a) fewer induced abortions taking place, b) induced abortions occurring under safer conditions, c) abortions continuing in high risk circumstances but improvements in post-abortion care result in fewer abortion-related deaths. Taken independently or together, these factors highlight the fact that abortion-related mortality does not happen in isolation, and that both the incidence and safety of abortion must be considered when developing and interpreting estimates of abortion-related mortality [16].

Among the causes of maternal death, abortion is likely the least well measured [17-19], and methodological advances in measuring abortion-related mortality have been slow to develop. While innovations in primary data collection and estimation methodologies are much needed, at the very least, studies that seek to measure maternal deaths due to abortion should endeavor to follow three simple recommendations: 1) Prioritize transparency, 2) Acknowledge limitations of data, and 3) Contextualize results.

Recommendations for collection and reporting of abortion-related mortality data

- Prioritize transparency
Specify data sources, clearly describe statistical models, and, where possible
make data, coding, and publications publically available/open access.

\section{- Acknowledge limitations of data}

Identify potential biases, describe hypothesized direction and magnitude of biases, and convey probable impact on results.

\section{- Contextualize results}

Facilitate interpretation of abortion-related mortality estimates by presenting and interpreting results within a context of abortion safety and incidence.

The examination of current and historical estimates of abortion-related mortality highlights both the importance of strengthening local and national level systems for the collection of routine health information as well as the importance of programmatic action to eliminate the criminalization of abortion, reduce abortion-related stigma, and increase access to safe abortion. As we move towards sustainable development goals beyond 2015 with a proposed aim of ending preventable maternal mortality (EPMM) [20], the need for valid and reliable estimates of abortion-related mortality has never been more pressing. The post-MDG development agenda that aims to improve global health, reduce health inequities, and increase accountability, requires new and novel approaches be tested to improve measurement and estimation of abortion-related mortality, as well as incidence, safety and morbidity.

\section{Competing interests}

The authors declare that they have no competing interests.

\section{Authors' contributions}

CG conceived of the commentary premise and led the coordination and drafting of the manuscript. OT, HJ, and BG participated in the design and construction of the arguments posited in the commentary and to drafting the manuscript. All authors read and approved the final manuscript.

\section{Author details}

${ }^{1}$ Ibis Reproductive Health, Oakland, California, USA. ${ }^{2}$ UNDP/UNFPA/UNICEF/ WHO/World Bank Special Programme of Research, Development and Research Training in Human Reproduction (HRP), Department of Reproductive Health and Research, World Health Organization, Geneva, Switzerland. 


\section{References}

1. WHO. Trends in Maternal Mortality 1990-2008. Washington, D.C: WHO, UNFPA, UNICEF, World Bank; 2010.

2. Say L, Chou D, Gemmill A, et al. Global causes of maternal death: a WHO systematic analysis. The Lancet Global Health. 2014;2(6):e323-33.

3. Kassebaum NJ, Bertozzi-Villa A, Coggeshall MS, et al. Global, regional, and national levels and causes of maternal mortality during 1990-2013: a systematic analysis for the Global Burden of Disease Study 2013. Lancet. 2014;384(9947):980-1004.

4. Fottrell E, Byass P. Verbal autopsy: methods in transition. Epidemiol Rev. 2010;32(1):38-55.

5. Deneux-Tharaux C, Berg C, Bouvier-Colle MH, et al. Underreporting of pregnancy-related mortality in the United States and Europe. Obstet Gynecol. 2005;106(4):684-92.

6. Turner LA, Cyr M, Kinch RAH, Liston R, Kramer MS, Fair M. Under-reporting of maternal mortality in Canada: a question of definition. Chronic Dis Can. 2002;23(1):22-30.

7. Kao S, Chen LM, Shi L, Weinrich MC. Underreporting and misclassification of maternal mortality in Taiwan. Acta Obstet Gynecol Scand. 1997;76(7):629-36.

8. Say L, Shah I. Maternal mortality and unsafe abortion: preventabe yet persistent. IPPF Med Bull. 2008;42(2):1-3.

9. Gerdts C, Vohra D, Ahern J. Measuring Unsafe Abortion-Related Mortality: A Systematic Review of the Existing Methods. PLoS One. 2013;8(1):e53346.

10. Grimes DA, Benson J, Singh S, et al. Unsafe abortion: the preventable pandemic. Lancet. 2006;368(9550):1908-19.

11. Walker D, Campero L, Espinoza H, et al. Deaths from Complications of Unsafe Abortion: Misclassified Second Trimester Deaths. Reprod Health Matters. 2004;12(24S):27-38.

12. Shahidullah M. A Comparison of Sisterhood Information on Causes of Maternal Death with the Registration Causes of Maternal Death in Matlab, Bangladesh. Int J Epidemiol. 1995;24(5):937-42.

13. Glasier A, Gülmezoglu AM, Schmid GP, Moreno CG, Van Look PFA. Sexual and reproductive health: a matter of life and death. Lancet. 2006;368(9547):1595-607.

14. WHO. Verbal autopsy standards: ascertaining and attributing cause of death. Geneva: WHO; 2007. http://www.who.int/healthinfo/statistics/ verbalautopsystandards/en/.

15. Shah I, Ahman E. Unsafe Abortion: Global and Regional Incidence, Trends, Consequences, and Challenges. J Obstet Gynaecol Can. 2009;31(12):1149-58.

16. Ganatra B, Tuncalp O, Johnston HB, Johnson Jr BR, Gulmezoglu AM, Temmerman M. From concept to measurement: operationalizing WHO's definition of unsafe abortion. Bull World Health Organ. 2014:92(3):155.

17. WHO. Unsafe abortion: global and regional estimates of the incidence of unsafe abortion and associated mortality in 2000. 4th ed. Geneva, Switzerland: World Health Organization; 2004. http://whqlibdoc.who.int/ publications/2004/9241591803.pdf.

18. Singh S, Fetters T, Gebreselassie $H$, et al. The estimated incidence of induced abortion in Ethiopia, 2008. Int Perspect Sex Reprod Health. 2010;36(1):16-25.

19. Grimes D, Benson J, Singh S, et al. Unsafe abortion: the preventable pandemic. Lancet. 2006;368(9550):1908-19.

20. Bustreo F, Say L, Koblinsky M, Pullum TW, Temmerman M, Pablos-Méndez A. Ending preventable maternal deaths: the time is now. The Lancet Global Health. 2013;1(4):e176-7.

\section{Submit your next manuscript to BioMed Central and take full advantage of:}

- Convenient online submission

- Thorough peer review

- No space constraints or color figure charges

- Immediate publication on acceptance

- Inclusion in PubMed, CAS, Scopus and Google Scholar

- Research which is freely available for redistribution 